\title{
Direct Realism and Spatiality
}

Susanna Salmijärvi

This paper questions Ingvar Johansson's statement that John Searle's theory of perception cannot be a direct realist theory of perception. First, it will be claimed that Johansson's criticism is based on an interpretation of an important claim in Searle's account, which is not the only possible interpretation of Searle's claim, and not true to other parts of his theory. Second, it will be argued that even if Johansson's interpretation of the claim is granted to him, his conclusion that Searle's theory is not a direct realist theory of perception does not follow.

In a broader perspective, the paper can be seen as a critical reconstruction of Johansson's theory of perception. Even if I disagree with parts of his criticism against Searle, it will become clear that I agree in large with his theory of perception.

\section{Introductory Remarks}

According to Ingvar Johansson (2003), John Searle's theory of perception cannot be considered as a "naive' (direct, common sense) realism" as Searle would have it (cf. Searle 1983:57). On a general level, he criticizes Searle for not being able to explain how something mental (a perception) can be in direct contact with something nonmental (a physical object or state of affairs). Searle does have a theory explaining the relation between a perceiver and the object perceived as an intentional relation. However, the question is what kind of relation an intentional relation is.

More specifically, Johansson claims that Searle's failure to account for the direct relation is based on a recurrent theme in Searle's theory of mind: the mind is in the brain. According to Johansson, the mind in brain-claim consists of two important parts: first, mental states are located in brains, and second, the spatial limits of mental states coincide with the limits of the brain. Since Searle explicitly claims that mental states are in brains, the first claim is very reasonable. However, it is not obvious that the second claim immediately follows from the first, since it is presupposed in the second claim that mental states can only be in brains in one way. In the first part of this paper, I will show that the 
second claim can be resisted when it is clarified that Johansson's interpretation of that claim is not the only possible one.

Johansson does not only claim that Searle's theory of perception cannot be direct realist - he believes that the theory implies a "monadological" theory of perception. According to this view, perceivers are enclosed inside brains like Leibnizian monads, without being connected to other perceivers or objects. In the second part of this paper, I will examine what is needed in order for Johansson's "monadological" conclusions to follow from his premises.

The speculative analysis in the second part of this paper, also leads to a tentative reconstruction of Johansson's theory of perception. Although the reconstructed view has many components in common with Johansson's theory, it will be suggested, in opposition to Johansson, that the relation between perceivers and objects perceived is a grounded relation. This view points away from Johansson's idea that perceptual acts literally extend through space and time.

\section{Interpretation}

\subsection{Johansson on Searle}

Originally, Johansson describes Searle's claim that the mind is in the brain as a combination of three sub-claims (Johansson 2003:237). In this section I will present these sub-claims and state two further sub-claims, based on what Johansson takes two of the original sub-claims to imply about perception. The third of the two original sub-claims will be mentioned in the end of this section, but since it makes no difference to the claims put forward in this paper, I will simply ignore the claim after having presented it. First, Johansson argues that Searle has located mental states inside brains:

(a) all mental states are localized in the brain. (Johansson 2003:237)

Searle repeatedly and explicitly claims that mental states exist in brains. Among other things, he writes that intentionality exists "entirely in the heads" of individuals (Searle 1997:427-428) and that each and every person's mental life is "inside" brains (Searle 1995:25). By specifying where the mental is located, Johansson takes Searle to contradict a traditional view in ontology. According to this view, matter exists in both space and time, if it exists at all, while mental states exist only in time, if they exist at all (Johansson 2003:236). Unlike Searle, the traditional 
view entails that mental phenomena have no spatial location or extension in space. According to Johansson, Searle's claim that the mind is located in the brain also entails that visual perceptions are located in the brain:

In everyday life I situate some of my mental experiences in my head, headaches and thoughts for instance, but not my visual perceptions, not my 'seeings'. According to Searle, however, all my mental states, nonintentional as well as intentional, are situated within my head, or, more precisely, in the brain. (Johansson 2003:240)

Johansson's additional claim about perception can be formulated thus:

(a)* all perceptual states are localized in the brain.

Second, Johansson claims that Searle has specified spatial limits for mental states:

(b) the spatial extension of mental states is no larger than the brain and not smaller than single neurons. (Johansson 2003:237)

He argues that Searle explicitly states a lower limit for mental extension when writing: "[s]ingle synapses, receptors and neurons are too small to have mental features" (Searle 1994:55-56). He further claims that Searle has implicitly specified an upper limit for mental extension - a limit which coincides with the limit of the brain. The basis for Johansson's latter conclusion are quotes in which Searle ascribe a location of mental states in brains or heads. According to Johansson, a crucial consequence of specifying spatial limits for mental states is that veridical perceptions must also be confined to the limits of the brain. Johansson writes:

A veridical perception, for instance, is not only partly caused by the brain of the perceiver, it is realized and exists wholly in the brain of the perceiver. (Johansson 2003:240; italic original)

Johansson's additional claim about perception can be formulated thus:

(b)* the spatial extension of perceptual states is no larger than the brain and not smaller than single neurons.

Third, according to Johansson, it is a consequence of our fallible science that:

(c) we do not know at the moment whether or not mental states have well-defined spatial borders. (Johansson 2003:237) 
Johansson takes Searle's claim that the mind is in the brain to imply the five sub-claims presented here. I will refer to the combination of these as the Mind in brain-claim, referring to Johansson's interpretations of Searle.

\subsection{Questioning Johansson}

\subsubsection{Mental States}

Let us first consider Johansson's interpretation of Searle's general claims about mental states, presented in (a) and (b). These claims must be considered first, since Johansson makes conclusions about Searle's theory of perception, based on his claims about mental states.

Johansson's interpretation of Searle's claim that mental states are located in brains is not controversial. As we have seen, Searle undoubtedly makes claims supporting the idea that mental states are located in the brain. ${ }^{1}$ The crucial claim is claim (b); for how should one understand Searle's statement that mental states exists "entirely in the heads" (Searle 1997:427-428) of individuals? Is the interpretation which Johansson makes, that "entirely" amounts to the spatial extension of mental states not being larger than the brain, really the only possible one, or are there some alternatives? The crucial question to be discussed here is not if, but how mental states are in brains.

First, note that when Searle makes the claim that mental states are entirely in the heads of individuals, and when he claims that mental life should be understood as situated inside brains, he is not explicitly discussing the spatial extension of mental states. Rather, Searle is opposing two views in social ontology. On the one hand, he opposes the view that collective intentional states are reducible to individual intentional states (Searle 1995, 1997). And on the other hand (Searle 1995), he opposes the view that there exists some kind of world spirit "floating over individual minds" (Searle 1995:25).

Johansson takes these claims to entail that mental states are in brains, as opposed to being outside of them. For example, Johansson talks about Searle's "conditions of satisfaction" as a distinction between brain-

\footnotetext{
${ }^{1}$ In Searle (1969, 1983, 1994 and 1995).

${ }^{2}$ According to Searle, intentionality should be explained in terms of conditions of satisfaction. Conditions of satisfaction (c.o.s.), are the conditions which must be fulfilled in order for an intentional state to be true, veridical etc. See further Searle
} 
internal and brain-external conditions (Johansson 2003:243), indicating that some conditions are located inside the brain, while other conditions are located outside the brain. ${ }^{1}$

There is a more plausible understanding of Searle's claim than Johansson's, when considering the social ontological context where Searle states that the mental is in the brain. His claim should be understood as saying that mental states are based on brain states, in opposition to being totally freestanding from the brain. ${ }^{2}$ Such a claim is different from Johansson's, since the claim that some entity is dependent on another entity is different from the claim that some entity is localized at the same place as the entity it is dependent on. Although Searle claims that the mental is located in brains, one can question Johansson's suggestion concerning how the mental is located in the brain. Seen in the contexts

(1983). According to Searle there is an ambiguity in the expression "conditions of satisfaction" between requirement, and the thing required. See further Searle (1986: 13).

${ }^{1}$ For clarity, it should be noted that Johansson's ascription of brain-internal and brain-external conditions of satisfaction to Searle's account, is a conclusion which Johansson draws from two claims made by Searle. The first kind of conditions of satisfaction are brain-internal since Searle's identifies these conditions of satisfaction with visual experiences. Since visual experiences, as a consequence of the mind in brain-claim, are brain-internal, the conditions must also be brain-internal. The second kind of conditions are brain-external since they are identical with the intentional object. In Searle's account an intentional object, or states of affairs, are ordinary physical objects, and therefore brain-external. One problem which Johansson points at in Searle's account is that Searle's identification of brain-internal requirement c.o.s. with intentional content on the one hand, and his identification of brain-external c.o.s. with the intentional object on the other, also leads to Searle mixing up the intentional content with the intentional object. This results from Searle's carelessness with making a clear distinction between the two kinds of conditions of satisfaction. See Searle (1983:13) and Johansson (1989:240f).

2 The same kind of argumentation can be found in Searle's theory of intentionality. One of his contributions to philosophy of mind is his thesis that intentionality is biologically based without being reducible to biological states. Searle writes: "On my view mental phenomena are biologically based: they are both caused by the operations of the brain and realized in the structure of the brain. On this view, consciousness and Intentionality are as much a part of human biology as digestion or the circulation of the blood. It is an objective fact about the world that it contains certain systems, viz., brains, with subjective mental states, and it is a physical fact about such systems that they have mental features" (Searle 1983:ix). 
where Searle states his mind in brain-claim, the suggested interpretation is more true to Searle's theory than the interpretation which Johansson's makes. ${ }^{1}$

Also note that since Searle never explicitly makes any claims about spatial limits of the mental, Johansson must ground his claim (b) on arguments. According to Johansson, (b) is a consequence of Searle's claim that mental states are located in brains, i.e. of (a). Johansson argues that Searle's locating of mental states in brains, also forces him to specify spatial limits for mental states. It was stated above that Johansson's idea behind this claim was based on his view that Searle contradicts a "traditional view" of ontology; Johansson argues that because Searle has located mental states in brains, he must also specify the limits of the mental, for the reason that everything existing in space has specific spatial limits (Johansson 2003:236). Johansson writes: "For every entity that exists in space one can ask, literally, what its spatial extension is. Searle has to face this question in relation to mental states" (Johansson 2003: 236). But does the claim that the spatial limits of the mental never exceed the limits of the brain (b) really follow from the claim that the mental is located in the brain (a)?

First, according to Johansson, Searle must say that the limits of mental states are identical with the limits of the brain, since mental states are in brains; the mental is located at the same place as the brain. However, if mental states are in brains by being based on brain-states, without being reducible to brain-states, the question exactly where mental states are located remains open. ${ }^{2}$ As noted above, the claim that some entity is dependent on another entity does not necessarily mean that the dependent entity is located at the same place as the entity it depends on. In this case, one cannot simply argue from the spatial limits of one entity and

\footnotetext{
${ }^{1}$ However, I do agree with Johansson when he claims that Searle is sometimes unclear whether he talks about conditions of satisfaction as identical with the intentional content, or as identical with the intentional object.

${ }^{2}$ I am aware that Searle very carefully claims that mental states can never exist anywhere else than in brains. However, I do not take this claim to imply that a whole mental state must be confined to the brain, in the sense that it never gets "in contact with" anything physical. Perceptual states can for example be taken to "reach" outside of the boundaries of brains, even though such directness is nothing spatial. This question will be discussed in part 3 .
} 
apply these limits also to the entity it is dependent on, since they are separate entities: (b) need not follow from (a).

Second, one can question Johansson's demand that Searle must specify which limits the mental has, because Searle has located mental states inside brains. Is it not possible to claim that Searle does not have to specify which possible limits the mental has by referring to science? In other words, is it not an empirical question which spatial limits the mental has, if it has any such limits at all? And before we know the answer, is it not a possible scenario that science in the future provide a world view according to which not everything existing in space has specific spatial boundaries?

Although the second question is interesting, I will leave to the reader to consider it further. In the next section, the first objection against Johansson will be developed, although in the context of perceptual states.

\subsubsection{Perceptual States}

Let us continue with considering Johansson's claims about perception in (a)* and (b)*. Johansson makes conclusions about perceptual states based on what Searle's says about mental states in general. But is everything said about mental states always applicable to perceptual states? Is it not possible that perceptions are special in some sense, such that they are sometimes the exception of what can be said about mental states in general?

Johansson cannot think there is anything special about perceptual states in Searle's account, ${ }^{1}$ since his conclusions concerning perception is based on claims which Searle makes about mental states in general. If this observation is correct, the criticism put forward in the previous part of this paper, should also apply to perceptual states: one could argue that components of perceptual states are located at another place than at the place where brain states are located. This is possible if perceptual states are dependent on brain states but not reducible to them. Such an analysis opens the door up for a certain theory of perception; perceptual states can be dependent on brain states physically, but does not have to be

\footnotetext{
${ }^{1}$ In the fictitious conversation between Johansson and Searle in Johansson (2003), the difference between mental states being presentational and representational is mentioned, but not discussed further by Johansson.
} 
"confined to" the limits of the brain. In other words, perceptions can exist in brains by being realized in brains physically, but perceptual states need not be identical to these physical brain states. In part 3 such theory of perception will be developed.

One reason not to accept Johansson's conclusions about perceptual states based on Searle's claims about mental states, is that Searle points to important differences between different kinds of mental states. Although intentional mental states have important components in common, ${ }^{1}$ at least one intrinsic feature makes perceptions different from other mental states, such as beliefs and desires. The distinguishing feature has to do with the way perceptions relate to their objects. Searle claims that perceptual experiences present their intentional object or states of affairs, while mental states such as thoughts and desires represent their objects and states of affairs. Contrary to representational states, perceptual states provide with direct access to the world:

If, for example, I see a yellow station wagon in front of me, the experience I have is directly of the object. It does not just "represent" the object, it provides direct access to it. The experience has a kind of directness, immediacy and involuntariness which is not shared by a belief I might have about the object in its absence [...] The visual experience I will say does not just represent the state of affairs perceived; rather, when satisfied, it gives us direct access to it, and in that sense it is a presentation of that state of affairs. (Searle 1983:45-46)

How should one understand Searle's claim that perceptions provide direct access to material objects and states of affairs by presenting their objects and states of affairs?

Searle's theory of perception is often analyzed as a typical intentional theory of perception. ${ }^{2}$ According to intentional theories of perception, visual experiences are always directed at objects and states of affairs in the world through intentional contents. This is a consequence of visual experiences having conditions of satisfaction. The way of understanding intentional contents having conditions of satisfaction, is that visual

\footnotetext{
${ }^{1}$ All intentional mental states have a propositional content, a direction of fit and conditions of satisfaction. See Searle (1983:1-78).

${ }^{2}$ For a contemporary introduction to the variety of intentional theories of perception, see Fish (2010: chapter 5).
} 
experiences can be veridical if the world is the way a content present it as being, just like beliefs are true or false depending on whether the world is as one believes it to be or not (Searle 1983:39). When a state of affairs is presented in an intentional content, the perception has intentionality, and is therefore about something. In virtue of intentional contents having conditions of satisfaction, an intentional connection is created between the perceiver and the object perceived. At least in this sense then, there is an intentional "relation" between the perceiving mind and the material object in the world that is perceived.

Johansson (2003) criticizes Searle's theory of perception on two closely connected points. First, Johansson claims that the theory cannot account for what kind of relation the intentional relation between a perceiver and the object perceived is. Johansson notes that in veridical perception, there must be some kind of relation between the perceived object and the intentional content, since the object, according to Searle's theory, should make the content satisfied by it (Johansson 2003:240f). Johansson is asking for a more detailed ontological description of the underlying relation(s) of intentionality, ${ }^{1}$ something which Searle never discusses in detail. According to Johansson, it is not enough to say that there is an intentional connection between a content and an object, since the question, what kind of relation the intentional relation is, remains unclear. This criticism is important from an ontological view point, and I will provide a tentative answer how such a relation could look in part 3 of this paper.

Second, in addition to the inability in Searle's theory to explain the nature of the intentional relation, Johansson also argues that he cannot explain the directness of perceptual acts. According to Johansson, Searle's mind in brain-claim makes perceptual states spatially limited to the boundaries of the brain, creating a spatial gap between a perceiver and the object perceived. ${ }^{2}$ On these grounds Johansson concludes that

\footnotetext{
${ }^{1}$ Johansson (1989) argues for a "level-ontology". According to Johansson, intentionality is not reducible to relations, but it is dependent for its existence on relations. See further Johansson (1989:212f).

${ }^{2}$ Johansson's point can be exemplified thus: "requirement conditions of satisfaction can be called brain-internal c-o-s [...] since these conditions of satisfaction are spatially internal to the brain and its intentional states $[\ldots]$ required conditions of satis-
} 
Searle's theory of perception must be indirect (Johansson 2003:239). But what does it actually mean that a perception is "directly" or "indirectly" of or about an object or state of affairs in the world?

It is clear that Johansson is searching for a spatially direct relation. $\mathrm{He}$ writes: "when we see a tree we are in direct contact with it in the same sense as when we hold on to it" (Johansson 1989:218). In Johansson's theory of perception, direct perception means that the perceived intentional object makes up a part of the perceptual act (Johansson 1989: 201). There are two ways in which an intentional object can be part of an act. Either all components of an intentional act - the content, act and object, are located inside brains, so that no gap results between them. Or, the perceptual act literally extends across or through both space and time to the object, ruling out every possible spatial gap between perceiver and the object perceived (Johansson 1989:216f).

In Searle's intentional theory of perception, the intentional object is not situated in the perceptual act. According to his theory, the intentional content determines conditions of satisfaction, which are satisfied by an external object (or state of affairs) in veridical perception. Given Johansson's demands of a direct realist theory of perception, then - Searle's theory of perception is not a direct realistic account of perception. In Johansson's words, his theory of perception is a representational, or indirect, theory of perception, meaning that intentional objects exist outside of intentional acts.

However, it is controversial what the claim that perceptions are "direct" actually amounts to. Should a theory of perception be described as direct realist only if the relation between a perceiver and the object perceived allows no spatial gaps (as Johansson has it)? Or, can it be describes as direct realist if the world is the way an intentional content present it as being, so that an intentional connection (whatever it is ontologically) will make our perceptions about objects and states of affairs in the world (as Searle has it)? There is no room in this paper to discuss these important questions. The point I would like to make though, is that Johansson's criticism of Searle's theory not being "direct" realist, cannot be evaluated before there are clear criteria of

faction $[\ldots]$ are spatially external to the brain and its intentional states" (Johansson 2003:243). 
what must be fulfilled in order for a theory to be a direct realist theory of perception.

\section{Implications}

Suppose that the arguments put forward against Johansson's interpretation of Searle's theory in previous section are misguided. Suppose that Johansson has made the correct interpretation of Searle's mind in brainclaim: Does it follow from the sub-claims that a "monadological" theory of perception must result, as Johansson has it?

The first thing to clear out is what Johansson means when he calls a theory of perception "monadological". Already in 1989, Johansson accuses science (physics, physiology, and perceptual psychology) for contributing a world view that is monadological. Johansson writes:

Within contemporary science one assumes that there are material things which emit or reflect some form of energy which moves towards other material things [so that a perception is caused] [...] But this perception is presumed to be completely spatially distinct from the material object which ultimately caused the perception. The perception is connected via body to a certain place in space and time, but is a whole completely closed within itself, which is mental and does not even have a spatial connection with other people's perceptions, even though they often have the same causes. (Johansson 1989:217; my italic)

Johansson's (1989) general criticism against the world view implied by science is analogous to the kind of criticism which Johansson directs at Searle's (2003) account. Johansson writes that Searle's account implies "our minds - but not our bodies - come out just as self-enclosed as they do in Leibniz's idealistic ontology. Since minds, according to Searle, are spatially enclosed in brains and two brains cannot be at the same place at the same time, neither can two minds" (Johansson 2003: 247). Applied specifically to perception, Johansson writes:

Applied to kissing and other nice things done intentionally together with a beloved one, Searle's analysis means the following. In such situations one's material body is literally in spatial contact with the beloved's body, but one's perceptions are wholly in one's own head, and the beloved's perceptions are wholly in the beloved's head. My 
mind is mine and her mind is hers, and never do they meet; not even partially! (Johansson 2003:249; my italics)

Based on these quotes, a central idea for a "monadological" theory of perception seems to be that perceptions are enclosed within brains, in the sense that they are not connected to other people's perceptions or objects, other than causally. I take the idea of being enclosed within brains as the defining feature of Johansson's "monadology"; from now on I refer to this interpretation by the term "monadology".

The crucial component for Johansson's conclusion that perceptions are monadological in Searle's account is claim (b)*. He must claim that the statement he ascribes to Searle in (b)*, that "the spatial extension of perceptual states is no larger than the brain" leads to the conclusion that perceptions are enclosed in brains. But the question is if one must accept that (b)* implies a monadology?

Let us remind ourselves how Johansson argued for claim (b)*. He said that (b)* was a consequence of Searle's implicit specification of spatial limits for mental states. Johansson claims that perceptions are partly caused by, realized in, and exists wholly in brains. Intuitively, the crucial component here seems to be the claim that perceptions exists "wholly in" brains; the question we need to discuss is if the claim that perceptions exists wholly in brains, implies that perceptions are enclosed in brains (i.e. that perceptions are "monadological").

There are three different ways to understand what it means that perceptions exist "wholly in" brains. Intuitively, "wholly in brains" could amount to the claim that all components of a perceptual state are located in brains. According to this interpretation, the perceptual content, perceptual act and the perceptual object are situated inside brains. One can find support for such an interpretation if one considers Johansson's theory of perception. Johansson (1989) claims that direct perception is about visual perceptual acts literally exceeding the boundaries of the brain, getting a direct spatial contact with the perceptual object. ${ }^{1}$ In contrast to Johansson's theory, one could understand "wholly in" brains as a

\footnotetext{
${ }^{1}$ Actually, Johansson rather uses the expression "intentional correlate" instead of "object" for perceptual intentionality. With this expression Johansson underlines that perceptual acts are not about objects in isolation. Rather, perceptual acts are always about objects and states of affairs in space and time; objects are always seen towards a background. See further Johansson (1989: 198).
} 
claim according to which no component of a perceptual state exceed the limits of the brain. ${ }^{1}$

However, the intuitive interpretation just described contradicts what Johansson explicitly says. As we have noticed, he claims that Searle's theory of perception is an indirect theory of perception (Johansson 2003: 239). According to this interpretation, "wholly in" brains should be understood as the claim that perceptual content and perceptual act are located in brains, while the perceptual object is "outside" of the brain. Johansson writes:

When two persons, $\mathrm{P}$ and $\mathrm{Q}$, look at each other, the following four statements are all true descriptions of the situation: (1) the mental event that is P's looking at Q is wholly located in the brain of P, and the mental event that is Q's looking at P is wholly located in the brain of Q; (2) the intentional object of P's looking is outside the brain of P, and the intentional object of Q's looking is outside the brain of Q; (3) $\mathrm{P}$ and $\mathrm{Q}$ have direct access to each other; (4) P and Q are not in any other relevant sense in spatial contact with each other. (Johansson 2003:239)

As we have already noticed, the problem which Johansson ascribes to this kind of theory of perception is that a spatial gap will result between perceivers and the objects perceived. ${ }^{2}$ According to this interpretation "wholly in" seems to apply to the problem with providing an explanation of the connection between perceivers and objects perceived. This view might be taken to imply a monadology about perception, in the sense that perceivers never get in spatial contact with material objects in pain of being wholly mental. As we have seen, Johansson's proposal to how one should bridge the spatial gap, is to allow the perceptual act to extend in space. But the question is if there is not a more commonsensical solution to this problem?

\footnotetext{
${ }^{1}$ For a more detailed description of Johansson's own theory of perception, see Johansson (1989: chapter 13, especially). See also Johansson (1998).

${ }^{2}$ Johansson describes the problem in terms of a distinction between two different kinds of conditions of satisfaction. But since one kind of conditions of satisfaction is identical with the intentional content, and the other kind is identical with the intentional object, I take it as a general problem of explaining the connection (or relation) between perceivers and the objects perceived.
} 
As I have promised in earlier sections, I will propose a tentative alternative way to bridge the spatial gap, based on Johansson's view on grounded relations. ${ }^{1}$ The idea with grounded relations is that "if $R x y$ is a grounded relation then $R$ is necessarily instantiated when both $x$ and $y$ are instantiated" (Johansson 1989:120). In other words, a grounded relation cannot fail to be instantiated, given that the two relata that are connected exists. Even if the relation cannot exist without its relata, the relata exists independently of each other, and independently of the relation. One example of a grounded relation is "has the same weight as". If a person $\mathrm{A}$, weighs $50 \mathrm{~kg}$, and a person $\mathrm{B}$, also weighs $50 \mathrm{~kg}$, then the grounded relation "has the same weight as" is instantiated as soon as the two persons exists. However, the two persons do exist, even though the relation is not instantiated.

Could one not argue that the relation between a perceptual content and act, and a perceptual object, is a grounded relation in veridical perception? Instead of following Johansson and making the perceptual act the spatial relation between a perceiver and the object perceived - one could claim that although content and act exist inside the brain and the object exists outside of the brain, they are connected by a grounded relation? In cases of veridical perception, satisfaction (as a relation) exists because both the intentional content and the intentional object exist.

This interpretation is in many ways in line with Johansson's theory of perception, but avoids the consequence that perceptual acts extend through space and time. Initially, there seems to be one problem with the suggested solution. According to Johansson, satisfied representational acts, such as thoughts and desires, are connected by a grounded relation (Johansson 1989:206). The reason why Johansson makes the perceptual relation spatial is therefore to ensure direct realism. He must believe that if there is no spatial perceptual contact between act and object, which is not the case if the spatial relation between act and object is a grounded relation, then direct realism cannot be true. He writes that if a veridical perception is "a mental feature, whose spatial extension covers the whole physical system consisting of the perceiving brain, the perceived object, and the space in between them [...] direct realism is true" (Johansson 2003:250; italics original). However, it has been emphasized

\footnotetext{
${ }^{1}$ See further Johansson (1989: chapter 8, especially).
} 
that the criteria which Johansson sets up for direct realism can be questioned, and does not rule out other possible ways to analyze direct realism. Perhaps it is enough for direct realism to make the relation between perceiver and the object perceived a grounded relation after all?

There is a third understanding of "wholly in" that does not imply perceptions being "enclosed in" brains in any sense. This interpretation requires a consideration of an important distinction which Searle makes between experience and perception. Johansson argues that Searle claims that perceptions are caused by, realized in and exits wholly in brains (Johansson 2003:240). However, to my knowledge, Searle never makes such a claim. Instead, Searle does say:

But where, then, is the visual experience in this [neurophysiological] account [of visual perception]? It is right there in the brain where these processes have been going on. That is, the visual experience is caused by the functioning of the brain in response to external optical stimulation of the visual system, but it is also realized in the structure of the brain. (Searle 1983:267; my italics)

In this quote, Searle clearly states that visual experiences are caused by, and realized in brains. But the fact that they are, does not exclude that some other components of a perceptual state are spatially located at another place than at the place where the visual experience is located. According to Searle's theory, to call something a "perception" means that it involves some kind of succeeding (Searle 1983:38f). This claim means that I have a perception of a black cat if there actually is a black cat in front of me that I see. On the other hand, if I have a hallucination of a black cat in front of me, I do not see anything at all. However, I do have an experience of a content that is indistinguishable from the experience I would have when I actually see a black cat in front of me. If I understand Searle correctly, an experience does not have to be directed at any object, but every veridical experience is. So, in the quotation above, Searle writes that visual experiences are caused by and realized in the brain, but with the distinction between experiences and perceptions in mind, nothing in the quotation excludes that there might be a perceptual relation and a relata (intentional object) situated "outside" the brain, as in the case of veridical perception.

The third understanding of "wholly in" brains does provide with an alternative way to understand Johansson's claim (b)*. He formulates the 
claim in terms of perceptual states, arguing that the spatial extension of perceptual states is no larger than the brain. From this claim he draws the monadological conclusion. If one takes Searle's distinction between experiences and perceptions seriously, Johansson's original claim in (b)* can be rewritten as the spatial extension of visual experiential states is no larger than the brain, and we can draw other conclusions than Johansson. The rewritten claim is compatible with the idea that components of perceptual states are situated "outside" of the brain. The tentative suggestion described above, according to which the connection between a perceiver and the object perceived should be described as a grounded relation, is one alternative.

It is not necessary to accept Johansson's conclusion that Searle's theory implies a monadology of perception, even if one accepts Johansson's premises (somewhat modified). Visual experiences can be caused by and realized physically inside brains, without the perceptual object having to be located inside brains. If the suggested reconstructed theory of perception can be accepted, then there also seems to be an alternative way to construct direct realism. ${ }^{1}$

\section{References}

Fish, W. (2010). Philosophy of Perception: A Contemporary Introduction, New York: Routledge.

Johansson, I. (1989). Ontological Investigations: An Inquiry into the Categories of Nature, Man and Society, London: Routledge.

Johansson, I. (1998). "Perception as the Bridge Between Nature and Life-World", in C. Bengt-Pedersen \& N. Thomassen (eds.), Nature and Life-World, Odense: Odense University Press.

Johansson, I. (2003): “Searle's Monadological Construction of Social Reality”, in D. Koepsill \& L. Moss (eds.), John Searle's Ideas about Social Reality: Extensions, Criticisms, and Reconstructions, Oxford: Blackwell, 233-255.

Searle, J. (1983). Intentionality. An Essay in the Philosophy of Mind. Cambridge: Cambridge University Press.

\footnotetext{
${ }^{1}$ I am very grateful to Anna-Sofia Maurin, Jan Almäng, Kristoffer Sundberg and Erik Dahl for comments on earlier versions of the paper.
} 
Searle, J. (1995). The Construction of Social Reality. New York: The Free Press.

Searle, J. (1997). "Précis of The Construction of Social Reality", Philosophy and Phenomenological Research, 57:427-428.

Searle, J. (2010). Making the Social World: The Structure of the Human Civilization, Oxford: Oxford University Press.

Smith, A. D. (2002). The Problem of Perception, Cambridge, Mass.: Harvard University Press.

Smith, D. W. (1990). “Thoughts”, Philosophical Papers, 19: 163-189. 